\title{
O USO DO SPRING NA ANÁLISE DE USO E OCUPAÇÃO DA TERRA NA MICROBACIA DO CORREGO DO CAVALO/MS (2005 e 2010)
}

Paulo Henrique Vieira ${ }^{1}$

\author{
Aline Cristina Alves da Silva²
}

Patrícia Helena Mirandola ${ }^{3}$

\begin{abstract}
Resumo: O presente trabalho busca gerar análises multitemporais referentes ao uso e ocupação da terra da micro - bacia do Córrego do Cavalo/MS, localizada no município de Três Lagoas/MS do ano de 2005 e 2010, juntamente com o mapa temático (uso e ocupação da terra) das determinadas datas. Para chegar a determinado objetivo foi preciso revisão bibliográfica e trabalhos de gabinete sobre o tema, utilização de softwares computacionais, o uso de SIG, no referente trabalho utilizou-se o SPRING ${ }^{\circledR}$,procedimentos operacionais, ou seja, processamento de dados orbitais, como imagens de satélite, organização das informações e divulgação dos resultados. Os resultados obtidos no determinado trabalho foram mapas temáticos de uso e ocupação da terra dos anos de 2005 e 2010, para podermos analisar as mudanças ocorridas na ocupação da terra na bacia hidrográfica do cavalo. A bacia hidrográfica sofreu grandes alterações nesses cinco anos, principalmente com a vinda das grandes empresas de celulose e papel, pode-se notar o aumento considerado do eucalipto na regia da bacia hidrográfica.
\end{abstract}

Palavras-chave: Mapa Temático. SIG. SPRING ${ }^{\circledR}$

\section{Introdução}

Bacia Hidrográfica ou bacia de drenagem de um rio, até a seção considerada, ou exutório, é a área de drenagem que contém o conjunto de cursos d’água que convergem para esse rio, até a seção considerada, sendo, portanto, limitada em superfície a montante, pelos divisores de água, que correspondem aos pontos mais elevados do terreno e que separam bacias adjacentes. O conjunto de cursos d'água, denominada rede 


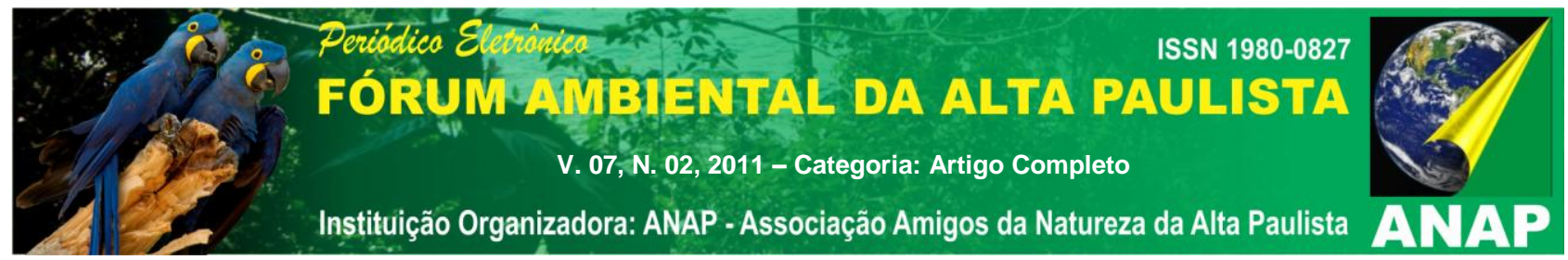

de drenagem, está estruturado, com todos os seus canais, para conduzir a água e os detritos que lhe são fornecidos pelos terrenos da bacia de drenagem.

A quantidade de água que atinge os rios está na dependência das características físicas

${ }^{1}$ Graduado no curso de Geografia Bacharelado pela UFMS/CPTL
${ }^{2}$ Graduado no curso de Geografia Bacharelado pela UFMS/CPTL
3Professora Adjunta do curso de Geografia na UFMS/CPTL

de sua bacia hidrográfica, da precipitação total e de seu regime, bem como das perdas devidas à evapotranspiração total e á infiltração. As características físicas são definidas pelas características morfológicas, representadas pelo tipo de relevo, forma, orientação e declividade da bacia de drenagem e pelos aspectos geológicos, representados pelas estruturas, tipos litológicos, mantos de intemperismo e solos. Além destes aspectos, a cobertura vegetal e o tipo de ocupação da bacia exercem também uma influência importante nas relações entre infiltração e escoamento superficial em uma bacia de drenagem.

As bacias hidrográficas vêm sofrendo grandes modificações ao longo do tempo, essas modificações quase sempre tem alguma ligação com atividades antrópica.

Os cenários ambientais construídos ou transformados pela ação do homem ocupam a maior parte dos sistemas ambientais. O homem transforma os espaços através de derrubadas de matas, da implantação de pastagens e cultivos, da construção de estradas, portos aeroportos, represas, da retificação e canalização de curso d água, da implantação de indústrias e áreas urbanas. (FLORENZANO 2002).

As imagens de satélite podem ajudar e muito nas transformações que as bacias hidrográficas podem sofrer, através da possibilidade de utilizar imagens de vários anos ou meses, podem-se fazer análises multitemporais e averiguar as mudanças que vêm ocorrendo.

No caso da bacia hidrográfica do cavalo situado entre as coordenadas geográficas de: Oeste $51^{\circ} 58^{\prime} 25,42$ " e $52^{\circ} 03^{\prime} 49,62$ " e Sul $20^{\circ} 57^{\prime} 15,03^{\prime \prime}$ e $21^{\circ} 03^{\prime} 48,75^{\prime \prime}$, localizado na região sul do município de Três Lagoas/MS.

Atualmente a região brasileira que mais vem se destacando em relação a expansão do eucalipto é o Estado de Mato Grosso do Sul, mais precisamente o município 


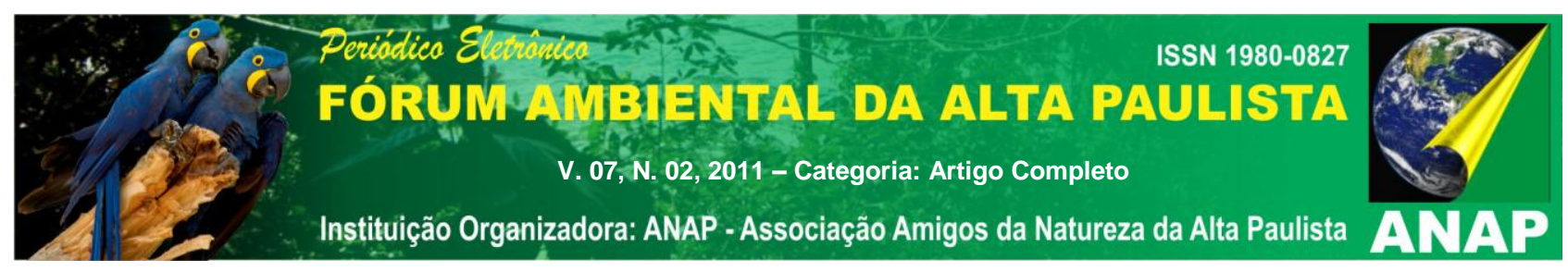

de Três Lagoas, que ganhou destaque no cenário nacional com a vinda de empresas multinacionais como a FIBRIA(fabricante de celulose) e Votorantim (fabricante de papel).

Entre 2005 e 2009, a área de plantio na microrregião de Três Lagoas duplicou de 152 mil para 308 mil hectares quase tudo de eucalipto. A previsão é expandir essa área para 1 milhão de hectares no ano de 2020. Fonte: www.canalvg.com.br

Essa expansão pode ser vista na área de entorno da bacia hidrográfica do cavalo, a expansão de eucalipto na região foi enorme, atualmente eucalipto e pastagem predominam na sobre as outras coberturas de terra.

Portanto o objetivo proposto por este trabalho é a criação de mapas temáticos de uso e ocupação da terra dos anos de 2005 e 2010, e fazer comparações das coberturas de terra presente no entorno da bacia hidrográfica do cavalo.

\subsection{Localização da área de estudo}

A bacia hidrográfica do córrego do cavalo localiza-se na região sul do município de Três Lagoas, que por sua vez, fica localizada na "costa leste sul mato-grossense.

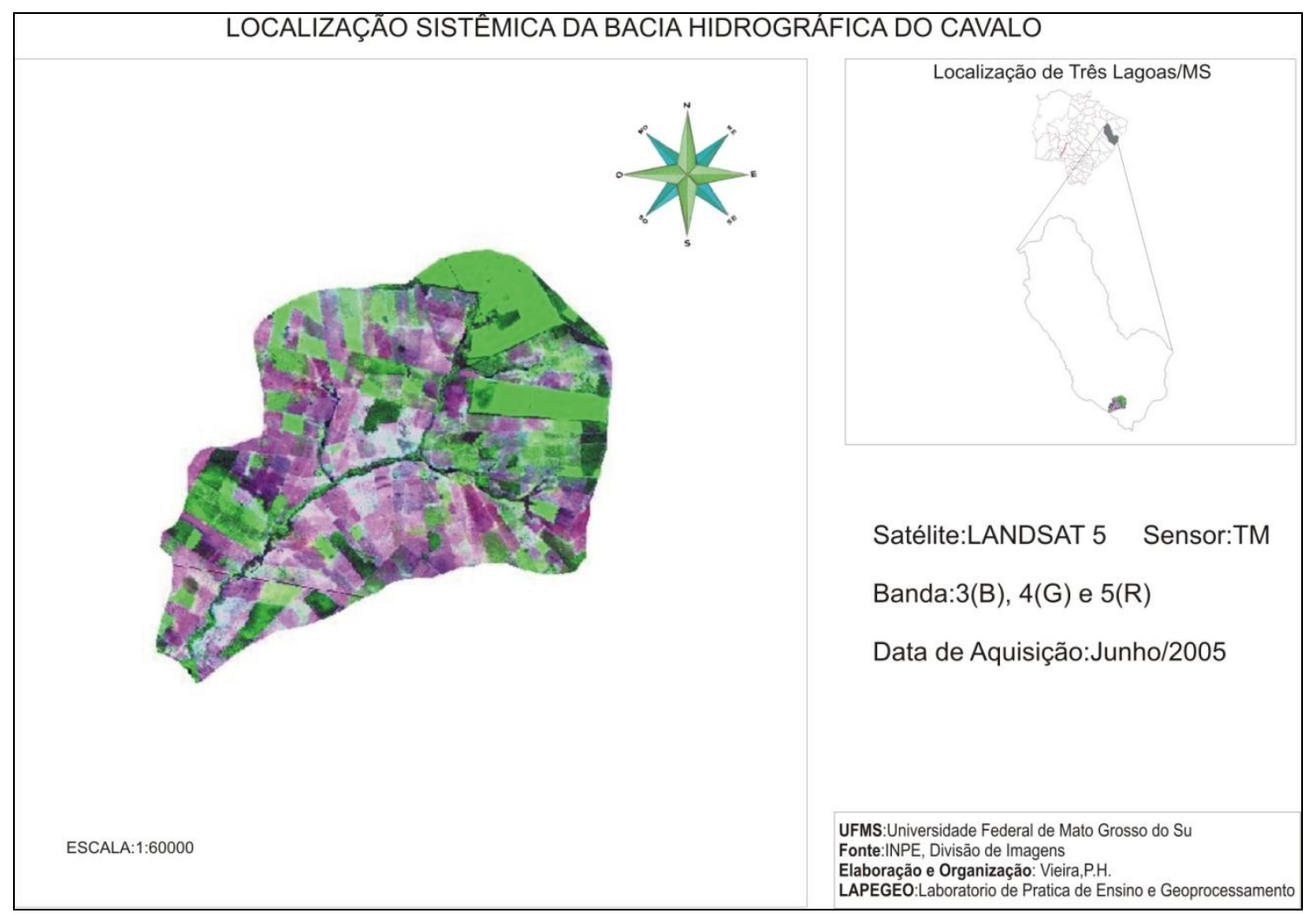




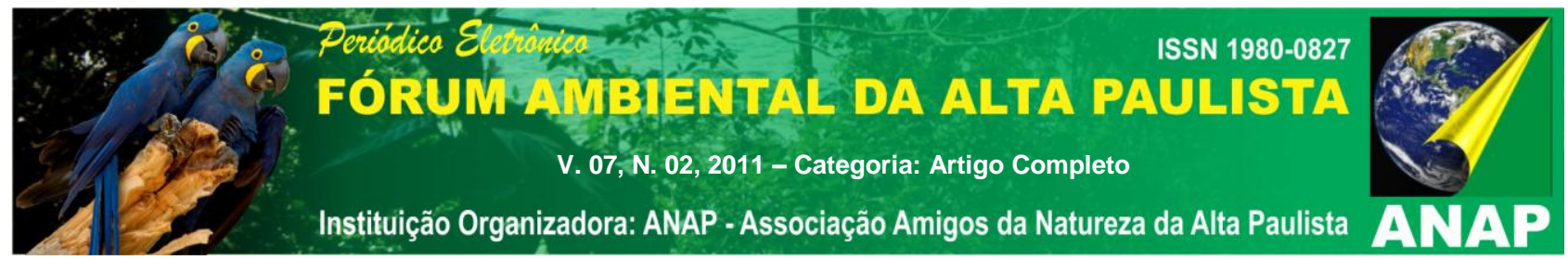

Figura 1 - Localização Sistêmica da Bacia Hidrográfica do Cavalo

\section{Desenvolvimento}

Os mapas de uso e ocupação da terra são de grande relevância nas analises espaciais, principalmente em um lugar tão complexo com uma bacia hidrográfica. E o SIG é uma ferramenta muito importante para produções destes mapas.

A importância dos mapas de uso e ocupação da terra nas análises geográficas é que o SIG possibilita a elaboração desses mapas, auxiliando nas análises eficazes de transformação do espaço geográfico, contribuindo assim para uma melhor gestão do espaço.

Fazer a junção de mapas temáticos com análise multitemporais, dará uma contribuição significativa em um planejamento sólido para uma ocupação mais responsável, evitando degradação da bacia, superpastoreio e outros problemas encontrados em uma bacia hidrográfica.

\subsection{SIG aplicado a gestão ambiental em bacias hidrográficas}

Após a segunda guerra mundial as tecnologias do geoprocessamento desenvolveram e começaram a ser usadas em pesquisa cientificas.

Antigamente as informações eram armazenadas em papel de fácil manuseio, mas encontravam-se dificuldades para análise integradas. Com o SIG e a capacidade de armazenamento em um Banco de Dados Geográficos, as pesquisas cientificas sobre os mais variados temas expandiram e as análises integradas tiveram resultados melhorados.

As pesquisas científicas que tinham como tema bacias hidrográficas se beneficiaram das Geotecnologias, com a capacidade de fazer mapas temáticos dos mais variados temas e datas diferentes, podemos fazer análises multitemporais, verificando as mudanças que possam ter ocorrido na área, expansão de determinadas coberturas de terra, aumento ou diminuição de áreas degradadas, etc.

Desde a sua concepção, um SIG deve ser compreendido como uma vigorosa ferramenta para apoiar a tomada de decisão por parte do usuário. A sua estrutura deve, 


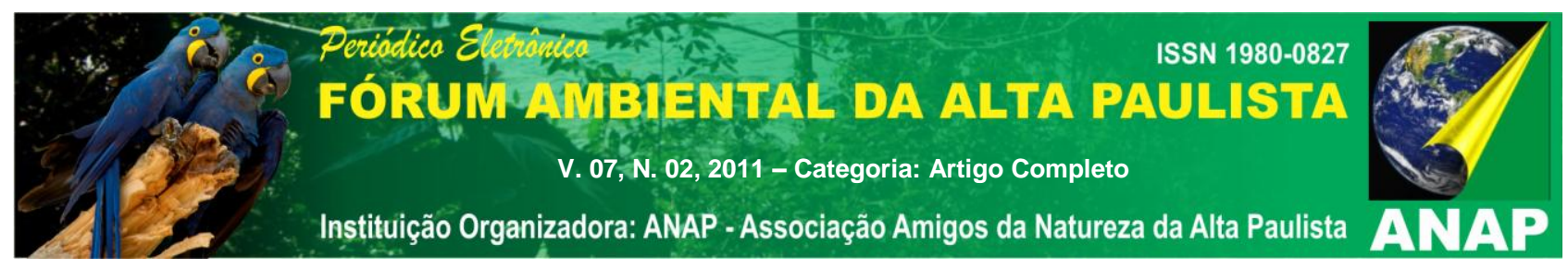

nesse sentido, ser muito bem planejada para que a interação homem-máquina se dê de maneira eficiente e atenda às necessidades dos usuários (FITZ 2008).

Os usuários nesse caso serão a população da região, o governo, planejadores ambientais e outras pessoas que possam se importar com o planejamento da bacia hidrográfica.

O SIG, no caso deste trabalho o SPRING ${ }^{\circledR}$ é uma ótima ferramenta para ser utilizada na gestão ambiental de bacias hidrográficas.

\subsection{Metodologia}

Etapa 1 - Revisão Bibliográfica: Fazer uma revisão dos temas que abordam o tema do trabalho.

Etapa 2 - Trabalhos de Gabinete: Verificar quais ferramentas serão aptas para chegar aos objetivos propostos

Etapa 3 - Utilização de softwares computacionais: No referido trabalho foi utilizado o software SPRING ${ }^{\circledR}$ 5.0.6, para a produção dos mapas temáticos de uso e ocupação da terra.

Etapa 4 - Procedimentos Operacionais: Processamento dos dados orbitais, ou seja, as imagens de satélite do Landsat 5

Etapa 5 - Organização das Informações: Refere-se a organização dos dados adquiridos.

Etapa 6 - Divulgação dos Resultados: Divulgação do Banco de Dados com as informações do trabalho, informações referentes à bacia hidrográfica do córrego do cavalo.

\subsection{Resultados}

Os resultados conquistados com este trabalho foram às produções de mapas temáticos de uso e ocupação da terra da bacia hidrográfica do cavalo e suas respectivas análises multitemporais dos anos de 2005 e 2010. 


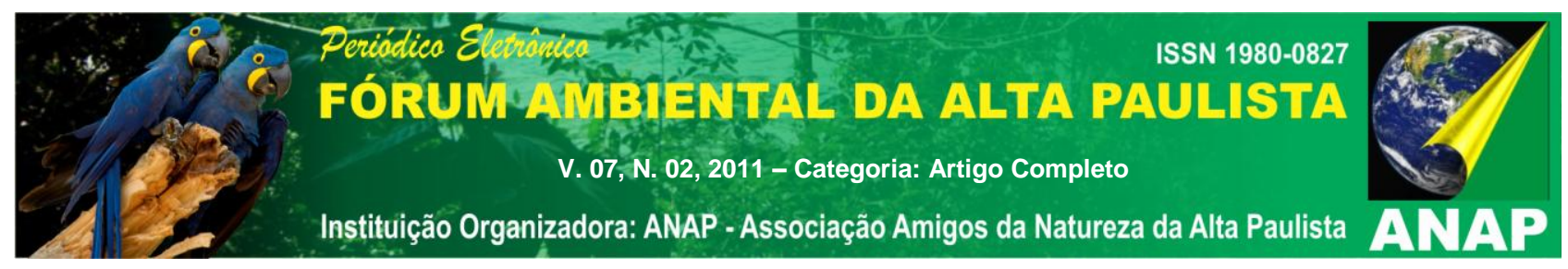

As cores utilizadas para representar as coberturas de uso da terra foram escolhidas de acordo com o Manual de Uso da Terra do IBGE (2006).

A micro-bacia hidrográfica do córrego do cavalo faz parte da bacia hidrográfica do Rio Verde, ou seja, o córrego do cavalo é um afluente do Rio Verde.

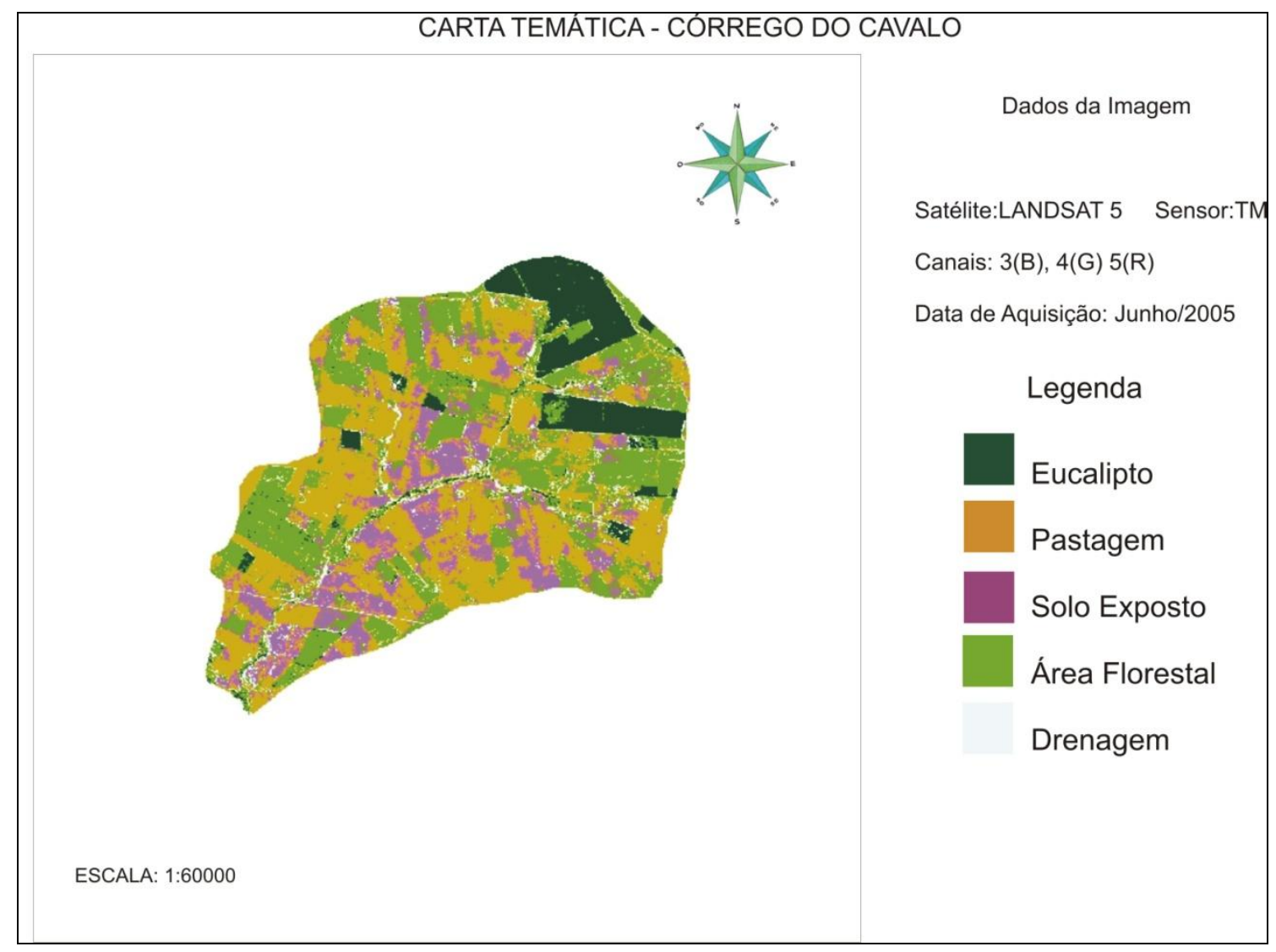

Figura 2 - Carta temática de 2005

Organização e Elaboração: Vieira, P.H.

Analisando o mapa de 2005 verifica-se que o que predomina no entorno do córrego do cavalo é o pasto, podemos verificar que em algumas áreas a mata auxiliar é ausente no seu lugar encontra-se pastagem. Essa grande quantidade de pasto é prejudicial para o entorno da bacia além de sofrer com o pisoteio do gado podendo acarretar erosões (laminar, ravinas e até agravar em voçorocas), o superpastoreio pode causar degradação ambiental. O superpastoreio pode ser o fator principal na degradação 


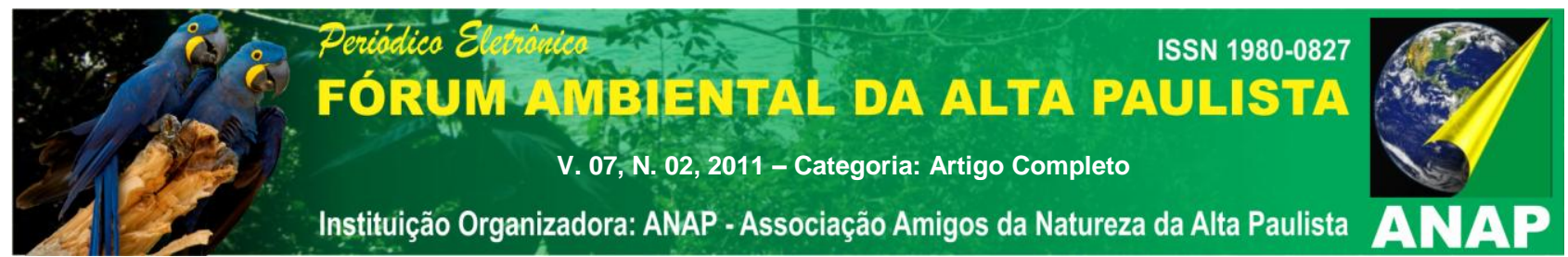

ambiental, causando metade dos danos avaliados na África e 3/4 em outras regiões em desenvolvimento [...] (FAO, 1986 apud ARAÚJO; ALMEIDA; GUERRA, 2005).

As áreas determinadas como solo exposto pode ser também solo sendo preparado para algum plantio seja ele temporário ou não.

Além de pastagem outra cobertura que predomina na região é a área florestal, determinada aqui também como mata ciliar, em algumas partes do córrego é notada a sua ausência, o que pode agravar problemas como erosão nas margens do córrego e assoreamento do rio.

O Eucalipto na área de entorno ainda é muito pequeno somente na parte nordeste da imagem notamos sua presença, lembrando que essa imagem equivale ao ano de 2005.

No quadro a seguir está demonstrando as percentagens de cada classe de cobertura da bacia hidrográfica do cavalo no ano de 2005

\begin{tabular}{|c|c|}
\hline \multicolumn{2}{|c|}{ Percentagem das classes de cobertura da terra (2005) } \\
\hline Pastagem & $38 \%$ \\
\hline Solo Exposto & $14 \%$ \\
\hline Drenagem & $5 \%$ \\
\hline Reflorestamento & $11 \%$ \\
\hline Área Florestal & $32 \%$ \\
\hline TOTAL & $100 \%$ \\
\hline
\end{tabular}

Quadro 1 - Percentagem das classes de cobertura da terra (2005)

Fonte: SPRING ${ }^{\circledR}$ 5.0.6

Analisando o quadro 1 fica evidente que pastagem e área florestal são as coberturas de terra que mais se apresentam na região da bacia hidrográfica( juntas somam $70 \%$ da área da bacia hidrográfica do cavalo). 

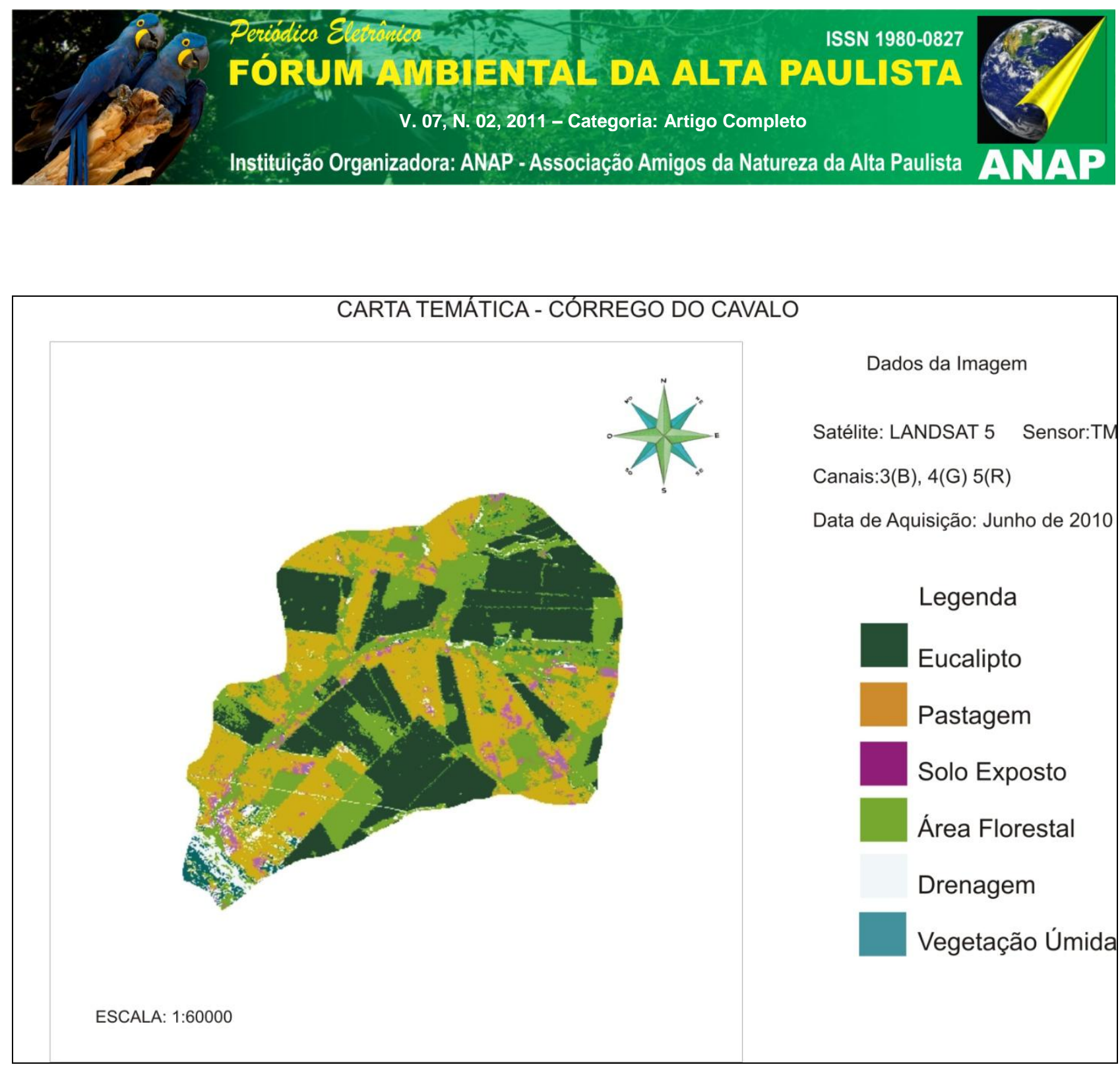

Figura 3 - Carta Temática de 2010

Organização e Elaboração: Vieira, P.H.

Analisando o mapa de 2010 fica evidente o crescimento do eucalipto na região, se tornando a cobertura de terra com maior extensão territorial no entorno da bacia hidrográfica.

Uma cobertura de terra que diminuiu drasticamente é o solo exposto ou solo nu, encontrado apenas em alguns pontos espalhados na área.

A área florestal houve apenas uma pequena redução na sua extensão, mas notamos que durante todo o percurso do córrego encontra-se mata auxiliar, melhorando assim o estado de equilíbrio do córrego.

$\mathrm{Na}$ área da pastagem também houve uma redução, mas ainda é uma das coberturas que mais se estendem na área da bacia hidrográfica. 


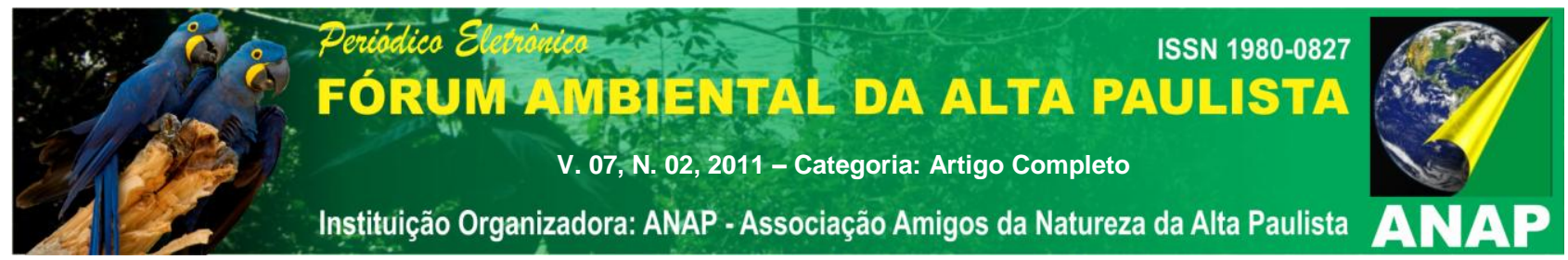

Em 2005 e 2010 verifica-se que a área de drenagem é muito pequena na bacia hidrográfica o principal motivo para que isso ocorra é que ambas as imagens são de Junho/2005/2010, que na região centro-oeste brasileiro é marcado pelo período de estiagem, então nesse período houve pouca chuva, explicando assim o fato do pouco de água encontrado na região.

No encontro do córrego do cavalo com o rio verde encontramos uma nova cobertura de terra vegetação úmida, marcado pela aquela vegetação encontrada dentro, do curso de drenagem ou próxima a ele, mas ficando úmida durante todo ano. Podemos notar que nessa área da bacia houve uma grande mudança visualmente falando entre 2005 para 2010.

No quadro a seguir verificam-se com percentagem as mudanças que ocorreram na área da bacia.

\begin{tabular}{|c|c|}
\hline \multicolumn{2}{|c|}{ Percentagem das classes de cobertura da terra (2010) } \\
\hline Pastagem & $31 \%$ \\
\hline Solo Exposto & $3 \%$ \\
\hline Drenagem & $3 \%$ \\
\hline Eucalipto & $33 \%$ \\
\hline Área Florestal & $28 \%$ \\
\hline Vegetação Úmida & $2 \%$ \\
\hline TOTAL & $100 \%$ \\
\hline
\end{tabular}

Quadro 2 - Percentagem das classes de cobertura da terra (2010)

Fonte: SPRING ${ }^{\circledR}$ 5.0.6

O quadro 2 mostra que a área de eucalipto triplicou na região passando de $11 \%$ em 2005 para 33\% em 2010.

O pasto e a área floresta que junto somavam 70\% atualmente chegam a 59\%, havendo uma pequena redução, durante esses 5 anos.

Outra cobertura que ganha destaque é a vegetação úmida encontrada apenas na foz do córrego tem apenas $2 \%$ da cobertura de terra do córrego

\section{Conclusão}




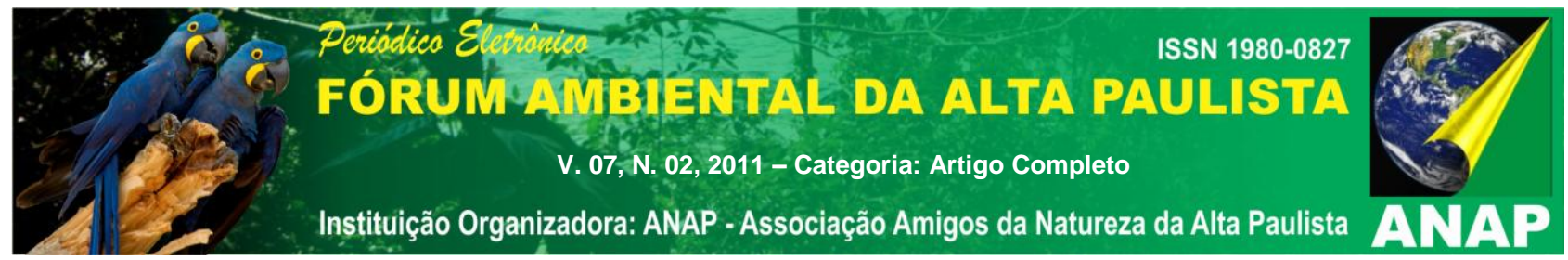

Cada vez mais há a necessidade de preservar os recursos hídricos, uma maneira de se fazer isso é fazendo análises e planejamentos sobre bacias hidrográficas. Fazer planejamentos de bacias hidrográficas é cada vez mais importante por ser uma área onde ocorre integração do meio natural com os seres vivos. Além disso, é uma área de fragilidade (área passível de problemas ambientais) de fácil reconhecimento e caracterização, em resumo podemos entender que a bacia hidrográfica funciona como um funil, toda a água que cai com a chuva escorre para um lago ou rio.

E este trabalho demonstrou que o SIG SPRING ${ }^{\circledR}$ é uma ferramenta que pode auxiliar no planejamento de um sistema complexo como uma bacia hidrográfica.

Através dos mapas foi possível a análise de uso e ocupação da terra no córrego do cavalo e verificar a expansão do eucalipto na região em torno de 5 anos, neste período o eucalipto triplicou sua área. Além do eucalipto o solo exposto diminui sua extensão e a pastagem teve uma diminuição, das outras coberturas nenhuma teve uma diferença alarmante.

É necessário que ocorra em bacias hidrográficas um planejamento de monitoramento que seja continuo, para analisar os eventos que possam estar ocorrendo nas bacias hidrográficas, e o SPRING ${ }^{\circledR}$ é uma ferramenta que pode estar auxiliando nesse monitoramento.

\section{Bibliografia}

ARAÚJO, G.H.de S; ALMEIDA, J.R. de; GUERRA, A.J.T. Gestão Ambiental em Áreas Degradadas. Ed.6. Rio de Janeiro: Bertrand Brasil, 2010.

CUNHA, S.B. Canais Fluviais e a Questão Ambiental. In: A Questão Ambiental. Diferentes Abordagens. Orgs.: Cunha, S.B. e Guerra, A.J.T. Rio de Janeiro: Editora Bertrand Brasil, 2003, p. 219-238.

CHRISTOFOLETTI, Antonio Geomorfologia. 2. ed. São Paulo: Edgard Blücher Ltda, 1981.

FITZ, Paulo Roberto. Cartografia básica. São Paulo: Oficina de Textos, 2008.

de Textos, 2008. Geoprocessamento sem complicação. São Paulo: Oficina 


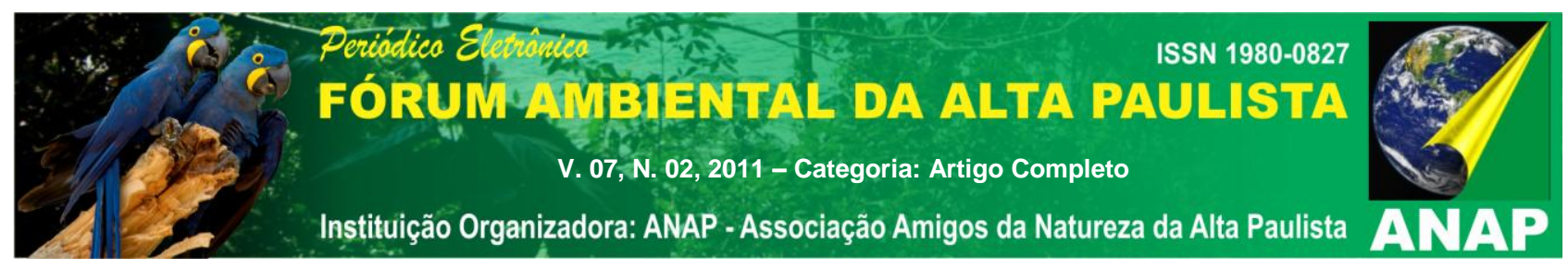

FLORENZANO, Tereza Galloti. Imagens de satélite para estudos ambientais. São Paulo: Oficina de Textos, 2002

,Teresa Gallotti. Iniciação em Sensoriamento Remoto. São Paulo: Oficina de Textos, 2007.

IBGE. Manual Técnico do Uso da Terra. Ed.2, n.7. Rio de Janeiro, 2006.

INSTITUTO NACIONAL DE PESQUISAS ESPACIAIS - INPE Fundamentos de Geoprocessamento - Tutorial. DPI - INPE, 2002 (mimeo).

GUERRA, A. T. J. \& CUNHA, S. B. da Geomorfologia uma atualização de bases e conceitos. Rio de Janeiro: Bertrand Brasil, 1998.

MIRANDOLA - AVELINO, Patrícia. Helena. Análise Geo - Ambiental Multitemporal para fins de Planejamento Ambiental: Um exemplo aplicado à Bacia Hidrográfica do Rio Cabaçal Mato Grosso - Brasil. Tese de Doutorado em Geografia do Programa de Pós Graduação em Geografia da Universidade Federal do Rio de Janeiro, 2006, 317 páginas.

<www.canalvg.com.br> acessado em 26/08/2011

$<$ www.inpe.br> acessado em 24/08/2011 